\title{
Mimicking Bone Chemical Composition Using Economical Materials for X-Ray Imaging Quality Assurance and Educational Purposes
}

\author{
Shyma M. Alkhateeb \\ Diagnostic Radiography Technology Department, Faculty of Applied Medical Sciences, King Abdulaziz University, \\ Jeddah, KSA \\ Email: smalkhateeb@kau.edu.sa
}

How to cite this paper: Alkhateeb, S.M. (2019) Mimicking Bone Chemical Composition Using Economical Materials for X-Ray Imaging Quality Assurance and Educational Purposes. Open Journal of Biophysics, 9, 83-87.

https://doi.org/10.4236/ojbiphy.2019.92006

Received: January 22, 2019

Accepted: February 22, 2019

Published: February 25, 2019

Copyright $\odot 2019$ by author(s) and Scientific Research Publishing Inc. This work is licensed under the Creative Commons Attribution International License (CC BY 4.0).

http://creativecommons.org/licenses/by/4.0/

\begin{abstract}
Imaging different bone sites for medical education requires the formation of bone-equivalent materials that mimic bone density. We investigated an economic imaging composition that characterizes bone density in imaging for quality assurance and educational purposes. Four different compositions were tested to reveal the best composition in simulating bone density in X-ray imaging. Hydrated lime was discovered to be the most suitable because it is durable (stiff and does not crumble), easy to source and process, and attenuates imaging $\mathrm{X}$-rays enough to resemble real bone. Hydrated lime provides a significantly better phantom than the other combinations used.
\end{abstract}

\section{Keywords}

Bone, Phantom, Quality Assurance, Education, Hydrated Lime

\section{Introduction}

Radiologic anatomical phantoms are commercially available for quality assurance and educational purposes. However, these phantoms are considered expensive and do not demonstrate all pathological complications. Therefore, materials that can convincingly simulate bone in X-ray imaging, for educational and quality-assurance purposes, have generated great interest.

Bone is composed of organic and inorganic compounds in the form of minerals. Living bone consists of $10 \%-20 \%$ water and $60 \%-70 \%$ minerals, with most of the rest comprising collagen and small amounts of other substances, such as proteins and inorganic salts [1]. Organic components, mostly collagen, represent $33 \%$ of total bone composition. Inorganic components consist of calcium (39\%), 
phosphate (17\%), carbonate (9.8\%), sodium (0.7\%) and magnesium (0.5\%) [2].

The mineral component can be approximated by hydroxyapatite (HA, $\left.\mathrm{Ca}_{10}\left(\mathrm{PO}_{4}\right)_{6}(\mathrm{OH})_{2}\right)$. Since the composition of real bone minerals is much more complex, and contains supplementary ions such as silicon and zinc, bone minerals have Ca:P ratios ranging from 1.37 - 1.87 [1]. Jastaniah (2016) produced a mixture of materials that contained egg shells and cement to reproduce bones in X-ray imaging [3]. Although egg shell is an environmentally friendly and economical substance, it is difficult to collect, maintain hygienically, and process.

The aim of this research was to mimic bone-chemical composition for X-ray imaging, by constructing an economical phantom with widely available materials, whose density closely matched that of bone. Materials closely resembling the mineral ingredients of bone, calcium (mainly), and collagen were used to construct the phantom. The resulting product of these constituents can simulate bone in different anatomical and pathological conditions, for both quality assurance and educational purposes.

\section{Materials and Methods}

Materials of a similar density to that of bone were chosen for X-ray imaging. Hydrated lime (calcium hydroxide $\mathrm{Ca}(\mathrm{OH})_{2}$ ) was used to represent calcium [4]. Since the molecular compositions of collagen and gelatin are almost identical [5], agar gelatin, an environmentally friendly and economical substance, was used to represent collagen. Agar is extracted from red seaweed (Rhodophyceae) and was discovered in Japan in the mid-seventeenth century and introduced to the west in 1859. Agarose, the structural unit of agar, is a linear polymer composed of (1-3)-linked agarobiose units of $\beta$-d-galactopyranose (1-4)-linked to 3,6-anhydro- $\alpha$-l-galactopyranose [6]. Potassium phosphatewas also used in the construction of the phantoms, representing the phosphate content in bone.

Four samples of different proportions of various components were prepared to investigate the chemical composition that best mimicked bone in X-ray imaging (see Table 1).

Hydrated lime is a building substance, purchased from a building materials store and manufactured by Arabian Industries, Riyadh, Kingdom of Saudi Arabia. Agar strips, originating from China, were purchased from a grocery store. The agar was ground to a powder, the lime was filtered, and all solid materials were blended together. The mixing process of four (10 cm-wide) shakes per second for 1 minute mixed all solid materials homogeneously. These materials were mixed with Safa (branded) water $\left(\mathrm{Ca}-\mathrm{Na}-\mathrm{HCO}_{3}-\mathrm{C} 1-\mathrm{SO}_{4}\right)$ [7]. The major ion concentrations and physical properties of the water (as indicated by the manufacturer) are illustrated in Table 2. One ppm is equivalent to one milligram of ions per liter of water (mg/L).

All solid mixtures (Table 1) were mixed with half the amount of water. For example, if $100 \mathrm{~g}$ of material constituted the solid part of the sample, $50 \mathrm{~mL}$ of water constituted the remainder. Due to their relatively negligible concentrations, 
Table 1. Four samples of different proportions of various components.

\begin{tabular}{cc}
\hline Sample number & Chemical composition of solid materials \\
\hline 1 & $100 \%$ lime \\
2 & $70 \%$ lime, $30 \%$ gelatin \\
3 & $40 \%$ lime, $30 \%$ gelatin, $30 \% \mathrm{KPO}$ \\
4 & $70 \%$ lime, $30 \% \mathrm{KPO}$ \\
\hline
\end{tabular}

Table 2. Major ion concentrations of Safa water, as indicated by the manufacturer, in parts per million (ppm) [7].

\begin{tabular}{ccccccccccc}
\hline $\mathrm{Ca}$ & $\mathrm{Mg}$ & $\mathrm{Na}$ & $\mathrm{K}$ & $\mathrm{Fe}$ & $\mathrm{HCO}_{3}$ & $\mathrm{SO}_{4}$ & $\mathrm{NO}_{3}$ & $\mathrm{Cl}$ & $\mathrm{F}$ & $\mathrm{BrO}_{3}$ \\
\hline 19.0 & 3.0 & 19.0 & 1.80 & 0.00 & 39.0 & 27.0 & 2.80 & 33.0 & 1.00 & $<0.01$ \\
\hline
\end{tabular}

the ions present in the water before mixing were ignored. For example, the weight of sodium ions $(\mathrm{Na}=19 \mathrm{ppm})$ in $1 \mathrm{~mL}$ of water is only $0.0190 \mathrm{mg}$, which is relatively insignificant. Mixtures were cast in molds to mirror bone dimensions. The X-ray machine used to image the samples was a Definium 6000, General Electric, 2009 with imaging parameters set as $10 \mathrm{~mA}, 50 \mathrm{kV}$, and $1.6 \mathrm{mAs}$.

\section{Results and Discussion}

The four samples, listed in Table 1, were formed and imaged together with shoulder bones detached from a real demonstration skeleton (Figure 1). This arrangement allowed the bones to act as a control.

The choice of ideal sample depended on the qualitative information gathered in Table 3. Durability of the samples means their ability to be re-used and stand-alone without crumbling. X-ray image acceptance of different samples compared to the real clavicle bone was obtained from highly experienced radiography personnel.

Sample one was clearly the best material and met all our specifications (Table 3). Despite sample two lacking durability (crumbling), it was the next best. Both samples three and four X-ray images were not acceptable because of the inhomogeneity that can be presented in their structure. The raw materials for samples one and two are easy to find and process. Therefore, two additional samples comprising the same materials in the same proportions as samples one and two, but of different sizes, were prepared. The additional samples were made in cylindrical-shaped molds of $2 \mathrm{~cm}$ diameter and $1 \mathrm{~cm}$ and $2 \mathrm{~cm}$ thickness. A radiograph of both samples, with a clavicle bone as a control, was obtained to examine X-ray intensity (see Figure 2).

Figure 2 shows the intensity match of different bone thicknesses with different thicknesses in sample one. Sample two has a higher absorption of X-rays for both thicknesses compared to bone. The difference in intensity seen in the middle of sample 1, with $1 \mathrm{~cm}$ thickness, reflects a change of $2 \mathrm{~mm}$ in thickness. 


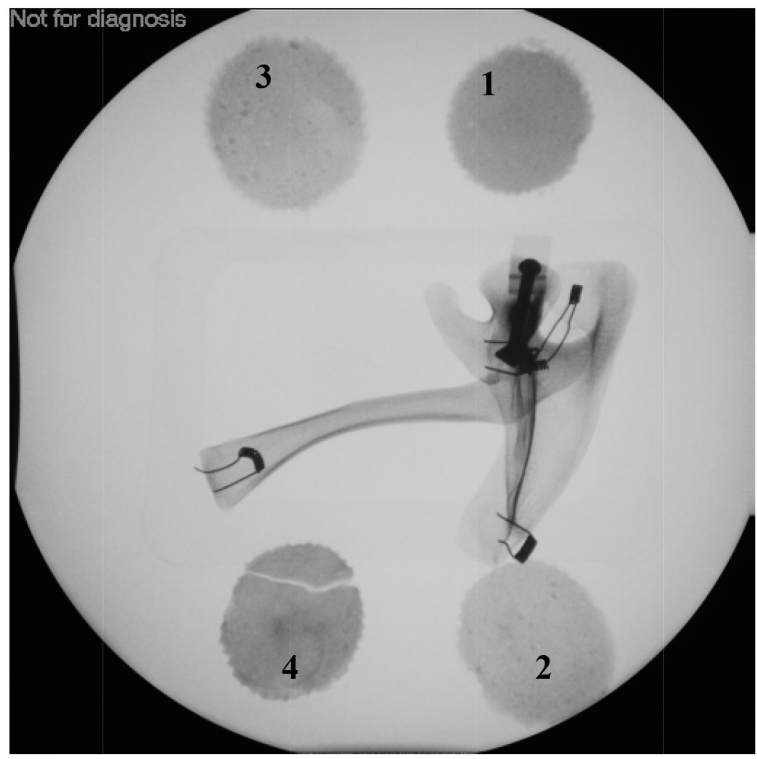

Figure 1. Radiograph of the four samples (Table 1) with the shoulder-bone controls.

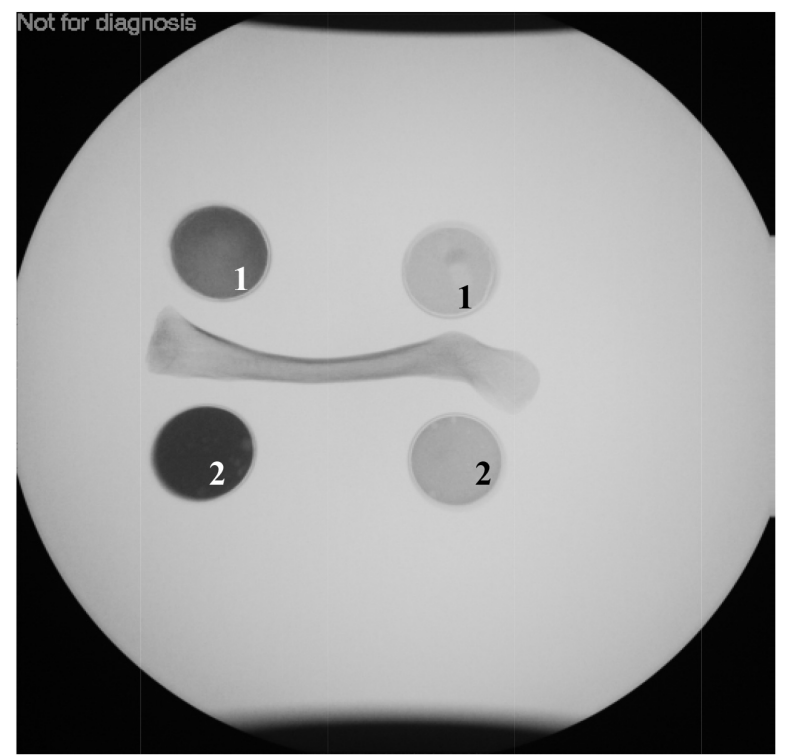

Figure 2. Radiograph of samples 1 and 2 with $1 \mathrm{~cm}$ (light) and $2 \mathrm{~cm}$ (dark) thicknesses, with a clavicle as control.

Table 3. Material choice characteristics.

\begin{tabular}{ccccc}
\hline Sample number & \multicolumn{4}{c}{ Sample characterization } \\
\cline { 2 - 5 } & $\begin{array}{c}\text { Easy to find } \\
\text { materials }\end{array}$ & Easy to produce & Durability & $\begin{array}{c}\text { X-ray image } \\
\text { acceptance }\end{array}$ \\
\hline 1 & Yes & Yes & Yes & Yes \\
2 & Yes & Yes & No & Yes \\
3 & No & No & No & No \\
4 & No & Yes & No & No
\end{tabular}




\section{Conclusion and Recommendations}

The idea of discovering a new economical material that mimics bone density in $\mathrm{X}$-ray imaging started when trying to make phantoms of different bone fractures and sites for medical education and quality assurance purposes. Different materials have been discovered in the literature, however, they are not economical, durable, nor easy to produce. Among the tested materials in this study, the most economical at mimicking bone in X-ray imaging was hydrated lime. Hydrated lime is durable (stiff and does not crumble), easy to find and process, and has a good X-ray image intensity compared with that of real bone. Future work should involve X-ray imaging testing of different hydrated-lime morphologies that simulate their real-bone counterparts.

\section{Acknowledgements}

All thanks to The Creator for His blessings. I would like to thank radiographers Mr. Shuraim Alyami and Mr. Hashim Alalawi for operating the X-ray machine, acquiring the radiographs, and optimizing the images. Special thanks to Dr. Saddig Jastaniah for qualifying the resultant images. I would also like to thank Editage (http://www.editage.com/) for English language editing.

\section{Conflicts of Interest}

The author declares no conflicts of interest regarding the publication of this paper.

\section{References}

[1] Cambridge, U.O. (2011) Structure and Composition of Bone. Structure of Bone and Implant Materials. https://www.doitpoms.ac.uk/tlplib/bones/structure.php

[2] Martini, F.H., Nath, J.L. and Bartholomew, E.F. (2012) Fundamentals of Anatomy and Physiology. 11 Edition, Pearson Education, Inc., London, England.

[3] Jastaniah, S.D. (2016) Novel Mixture of Materials Produces Bone- and Soft Tissue-Like Imaging Density. Open Journal of Biophysics, 6, 90-97. https://doi.org/10.4236/ojbiphy.2016.64010

[4] Herrin, M. and Mitchell, H. (1961) Lime-Soil Mixtures. In 40 th Annual Meeting of the Highway Research Board, Highway Research Board.

[5] Djabourov, M., Lechaire, J.-P. and Gaill, F. (1993) Structure and Rheology of Gelatin and Collagen Gels. Biorheology, 30, 191-205. https://doi.org/10.3233/BIR-1993-303-405

[6] Imeson, A. (2009) Agar, in Food Stabilisers, Thickeners and Gelling Agents. Wiley Online Library, Hoboken. https://doi.org/10.1002/9781444314724.ch3

[7] Al-Zahrani, F.S.A., Albaqshi, H.A.A., Alhelal, G.A.M., et al. (2017) Bottled Water Quality in KSA. IJISET-International Journal of Innovative Science, Engineering \& Technology, 4, 2348-7968. 